\title{
Rehabilitation and Strengthening of Aged Steel Railway Bridges in Japan
}

\section{Weiwei Lin*}

Department of Civil and Environmental Engineering, Waseda University, Tokyo, Japan

\begin{abstract}
In Japan, nearly a half or even more of the existing bridges with a span exceeding 15 meters were predicted to be over 50 years old in next 10 years. Appropriate repair, strengthening, or replacement work should be performed on aged steel bridge structures to ensure their performance in service condition. A novel strengthening method using rubber-latex mortar, glass fiber reinforced polymer plates, lightweight rapid hardening concrete, and reinforcement bars is proposed for strengthening short-span steel railway bridge superstructures and for improving the seismic performance of aged column structures. To confirm the effectiveness of the strengthening method, loading tests were performed on test specimens for short-span steel railway bridges, longitudinal-lateral beam connections as well as steel columns. Numerical models were also built to simulate the structural behavior of both original and strengthened steel structures. According to the obtained results, the present renovation method can significantly enhance both rigidity and load carrying capacity of short-span steel bridge superstructure, connections, and column structures, resulting in the extension of the residual fatigue service life of bridge tarp structures and improvement of seismic performance of column structures.
\end{abstract}

Keywords: Rehabilitation; Aged steel railway bridges; Static loading test; Connection; Numerical simulation; Rubber-latex mortar; Lightweight rapid hardening concrete; GFRP plate

\section{Introduction}

In recent years, rapid deterioration of steel bridge structures has become a serious technical and economic problem in many countries including Japan. As shown in Figure 1, there are around 60,000 steel bridges (with span length longer than $15 \mathrm{~m}$ ) currently in Japan, and approximately $70 \%$ of them have been used for over 30 years. After the warning of "American in ruins", the bridges built in the rapid economic growth period (1950s and 1980s) began to have aging problems in 2010s and "Japan in ruins" was also become a concern. Taking the bridges older than 50 years (the bridge design service life) in Japan as an example, the ratio has increased remarkably from $6 \%$ in 2006 to $20 \%$ in 2016, and it is predicted to be around $47 \%$ in 2026 .

With aging, corrosion and fatigue become major causes of deterioration of steel bridges, and their damages seriously affect the durability of steel bridges. In 2003, nearly complete fracture of a lateral beam was confirmed in the Funatonishi bridge ( 35 years old) in Tokushima Prefecture, which was mainly due to fatigue. In 2004, severe corrosions of main girder was confirmed in the Ukedogawa bridge (40 years old) in Fukushima Prefecture. In 2006, severe corrosions on bearing and main girder were observed in the Oise Ohashi bridge in Miyagi Prefecture. In the same year, fatigue induced cracks were found in a main girder in the Yamazoe bridge (35 years old) in Nara Prefecture. In 2007, and a diagonal member of three steel truss bridges was fractured due to corrosion, including the Kinogawa ohashi bridge (44 years old) in Mie Prefecture, the Honjo Ohashi bridge (41 years old) in Akita Prefecture, and the Tsutsui Ohashi bridge (39 years old) in Oita Prefecture.

Therefore, appropriate repair, strengthening, or replacement work should be performed on aged bridge structures to ensure their good performance in service condition. Considering the relatively high cost for replacing as well as the great impact on the public transportation, repair and strengthening on the aged bridges is generally more preferable both environmentally and economically than to demolish and replace them by building new bridges.

On this background, the research on strengthening existing steel railway bridges has been performed by many engineers and scholars around the world, including the group the author belongs to. The

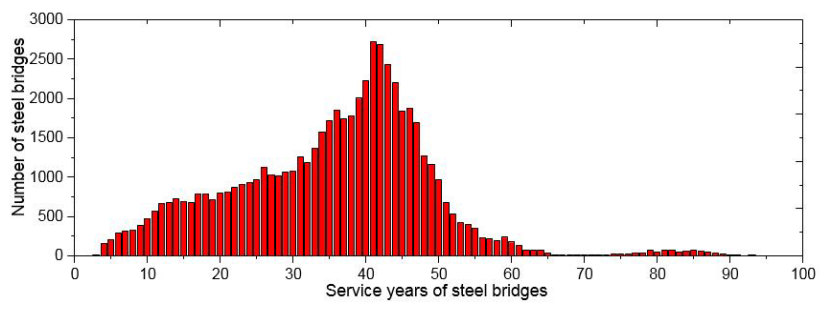

Figure 1: Service years of steel bridges in Japan [1].

strengthening method proposed in the author's group and three case studies for confirming the real effectiveness of the proposed method will be introduced briefly in this paper.

\section{Methodology}

\section{Rehabilitation strategy}

Typical deteriorations of steel bridges include section loss or reduction due to corrosion, crack or member fracture due to fatigue, release or fall off of bolts, and large deformation etc. For steel railway bridges, however, fatigue is more severe than other problems due to relatively large live load ratios in comparison with other bridges. Main purpose of this study is to propose a strengthening method for aged short-span steel bridge superstructure and substructure (e.g. bridge pier). For steel bridge superstructure, the fatigue of structural steel due to repeated live loads is the major concern for the busy railway system. For bridge substructures in Japan, however, the improvement of seismic performance is the main purpose. As the fatigue is closely related to stress levels due to live load while the seismic performance is related to the ultimate load, increases of stiffness and the load carrying capacity are the main purpose of the strengthening.

*Corresponding author: Weiwei Lin, Department of Civil and Environmental Engineering, Waseda University, Shinjuku-ku, Tokyo 169-8555, Japan, Tel: +81 3-3203-4141; E-mail: linweiwei@aoni.waseda.jp

Received March 19, 2018; Accepted March 29, 2018; Published April 04 , 2018

Citation: Lin W (2018) Rehabilitation and Strengthening of Aged Steel Railway Bridges in Japan. J Civil Environ Eng 8: 305. doi: 10.4172/2165-784X.1000305

Copyright: ( 2018 Lin W. This is an open-access article distributed under the terms of the Creative Commons Attribution License, which permits unrestricted use, distribution, and reproduction in any medium, provided the original author and source are credited. 
As shown in Figure 2, the philosophy of the proposed method is to change the steel section to the composite section by integrating with new structural materials, which in turn increase the stiffness and load carrying capacities, thereby extending the residual fatigue service of bridge superstructures and improving the seismic performance of aged steel piers. By considering the constructability, anticorrosion, and less damage for existed structural members, FRP plates, rubber-latex mortar, rapid hardening concrete and reinforcing bars were used in this method. Concrete and mortar, including SBR latex, shows various abilities especially in adhesion bonding, waterproofing, shock absorption and abrasion resistance. Rubber-latex mortar was used in this study not only for increasing the bond strength on the steel-concrete interface, but also for reducing the noise and avoiding the structural steel corrosion in the service stage. Lightweight rapid hardening concrete was applied for rapid construction, light self-weight, to also to reduce both service stress and vibration noise levels. For structural maintenance and rehabilitation of the railway structural members, rapid construction was the key. Therefore, rapid hardening concrete with relatively high early age strength and light weight is the special choice for this strengthening method. In this strengthening method, FRP plates are used as the formwork for concrete casting and their contribution to structural stiffness and load carrying capacity are not considered in the design. Besides, reinforcing bars were used for controlling the crack width after concrete cracking. In general, the total procedures can be finished very quickly and will not interrupt the public transportation.

\section{Numerical simulation}

In addition to the loading tests, numerical analyses were also performed to confirm the real effectiveness of the proposed strengthening method. Particularly for the original steel section, as the loading test was stopped in the elastic stage to avoid the plasticity of the specimen, the numerical analysis is necessary to accurately estimate its load carrying capacity.

The modelling of test specimen was carried out in three dimensions using the finite-element method and DIANA software. For each structural type, two numerical models were built for simulating the test specimens before and after strengthening respectively. In the numerical simulation, solid elements were used to simulate the concrete, shell elements were employed to model the steel girder and GFRP plates, and re-bar elements were used for modelling the reinforcing bars in the concrete. To account for the slip between concrete and structural steel, interface elements were used [1].
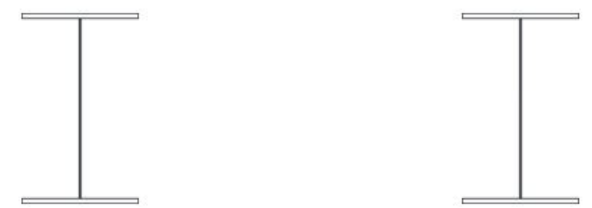

(b) Steel section

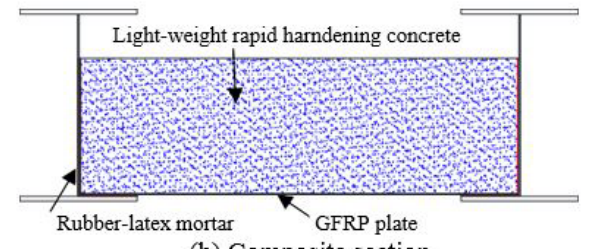

(b) Composite section

Figure 2: Strengthening concept.

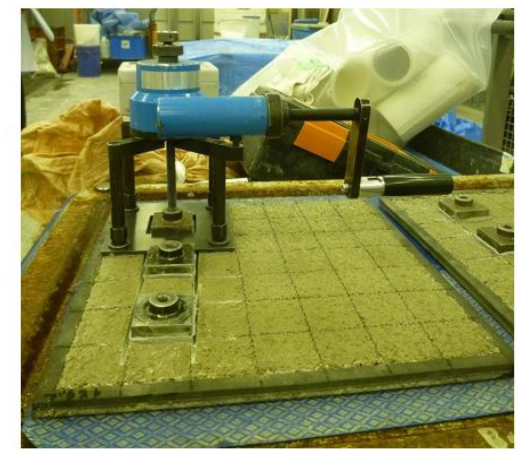

Figure 3: Bonding test for steel-concrete interface.

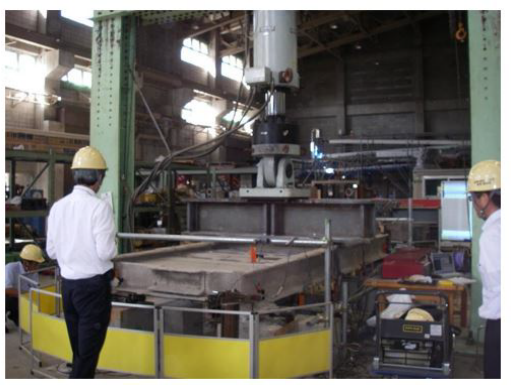

Figure 4: The static loading test setup.

Material tests were performed and the test results were used in the numerical analyses. In terms of the material properties, the stress-strain curve due to JSCE [2] and the experimental tension-stiffness curve [3] were employed to simulate the compression and tension behavior of concrete. The stress-strain curve with strain hardening recommended in JSCE specification [4] was used to simulate structural steel. The bonding test shown in Figure 3 was also performed, and the experiment-based bond-friction inter-face model was employed to simulate the composite action between the steel girder and the concrete.

\section{Case Studies}

In this paper, three case studies based on laboratory tests, including strengthening of short-span railway bridge superstructure, longitudinaltransverse beam connection, and columns, were reported.

\section{Case-1: Strengthening of short-span railway superstructures}

Description of the test specimen: The steel railway bridge superstructure used for loading tests was originally built in 1912 and removed from service in 2004. The bridge has two longitudinal steel girders and four transverse beams between them. The specimen was $4380 \mathrm{~mm}$ in length and was simply supported at a span of $3870 \mathrm{~mm}$. In the strengthening, the concrete thickness was $200 \mathrm{~mm}$ with a width of $1530 \mathrm{~mm}$ [5-7]. GFRP plates were used as formworks and shear connection devices with the concrete. Reinforcing bars of D13 nominal diameter were used for both longitudinal and transverse reinforcing bars in the concrete slab. Based on the span length and sectional dimensions of the composite girder as well as the design load of the real bridge, the equivalent experimental loads were determined. The design service load was determined as $125 \mathrm{kN}$ while the design ultimate load was determined as $160 \mathrm{kN}$ according to the current railway bridge design specification. Before strengthening, a static test was performed on the old steel bridge with the maximum load of $33.8 \mathrm{kN}$. The steel bridge was tested again after sterngthening was performed, as shown 
in Figure 4. Numerical models of the old steel bridge before and after strengthening were built, as shown in Figure 5.

Results and discussion: As mentioned above, fatigue is a major concern for the target bridge superstructure. Therefore, the effects of the proposed method in reducing the stress (or increasing the rigidity) in service condition is a major concern and the test results within elastic range are reported.

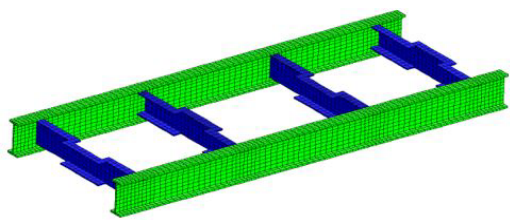

(a) Steel bridge

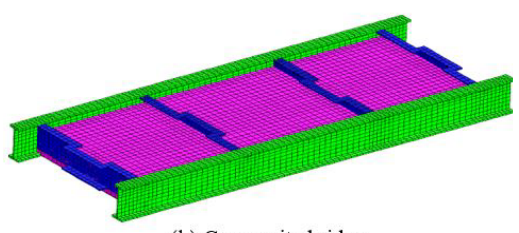

(b) Composite bridge

Figure 5: Numerical models of the short span railway bridge.

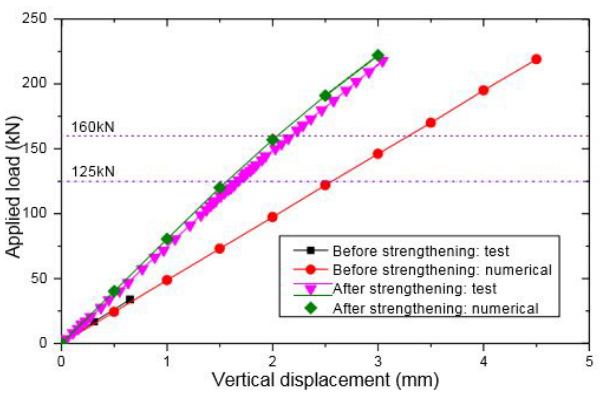

Figure 6: Applied load-displacement relationship.

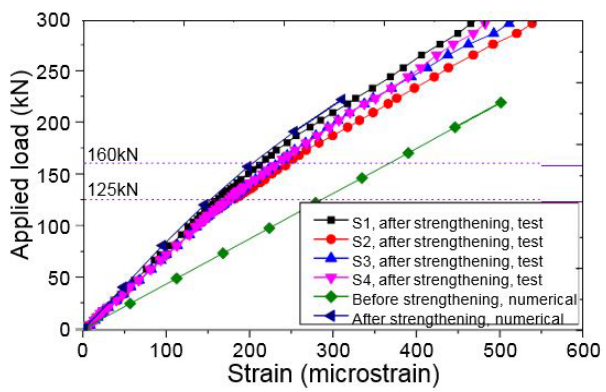

Figure 7: Applied load-strain relationship.
The load-displacement curve obtained from the static loading test of the original steel girder was compared with that of steel bridge after strengthening. The vertical deflection was taken at the bottom mid-point of the bridge. Before strengthening, a simple loading test was performed $(\mathrm{P}<33.8 \mathrm{kN})$ to generate the load-displacement curve of the original old steel railway bridge. The numerical results were also provided to compare with the experimental results. For the strengthened bridge model, "fully composite" assumption was used between different structural members.

When applied load was smaller than $300 \mathrm{kN}$, the load- deflection response was given in Figure 6. The experimental results from both original and strengthened specimens were illustrated and compared with numerical results. The comparison indicates that the numerical results agree well with the experimental results in the initial loading stage $(\leq 160 \mathrm{kN})$ for both original and strengthened specimens. When the applied load was larger than $160 \mathrm{kN}$, the rigidity of strengthened bridge became smaller and the load-displacement curve deviated from the numerical predictions. The design load of the target bridge was about $125 \mathrm{kN}$, which was much smaller than $160 \mathrm{kN}$, thus the strengthened railway bridge will be in the elastic stage under the service load. Besides, the comparison indicates that the rigidity of the strengthened bridge superstructure was increased by around 30\% in comparison with that of the original specimen. Therefore, rigidity increase of the aged bridge superstructure can be confirmed.

In addition, normal strain at mid-span section was also measured. Four strain gauges, denoting S1, S2, S3, and S4, were employed on the lower surface of the bottom steel flange. Similarly, theoretical results of the normal strain of original and strengthened girders were also provided, as shown in Figure 7. It is found that when the applied load was smaller than $160 \mathrm{kN}$, the numerical strain results on the bottom flange of the steel girder in strengthened bridge agree well with the test results, demonstrating that the strengthened bridge can be treated as fully composite structure in the service stage. When the load was larger than $160 \mathrm{kN}$, the strain on the steel bottom flange increased quickly with the applied load increase. Furthermore, the comparison of the numerical strain results between original and strengthened bridge indicates the significant reduction of the normal strain (or stress levels) of the structural steel, which in turn demonstrates the great extension of the residual service life.

\section{Case-2: Strengthening of longitudinal-transverse beam connections}

Description of the test specimen: A specimen was designed according to the real size of a longitudinal and transverse beam connection in a railway bridge in Japan. The longitudinal beam was kept to perform the loading test, but the transverse beams was cut short and used to transfer the load in the experiment for simulating the truck load from the rail. The specimens was $2.1 \mathrm{~m}$ in length and was simply supported at a span length of $2 \mathrm{~m}[8,9]$. Vertical stiffeners were welded at support points to prevent shear buckling failure and crippling of
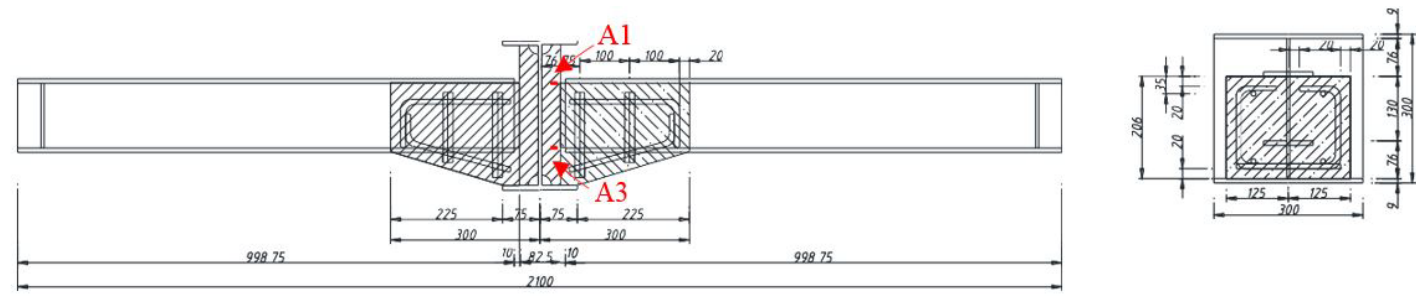

Figure 8: Dimensions of the connection after strengthening 
the web before flexural failure. The test specimen was supported by a roller system at two ends. The size dimensions of the connection after strengthening is shown in Figure 8, and the set-up of the loading test is shown in Figure 9.

Totally 2 steel joints were prepared for the test, one of them are subjected to positive bending moment, and the other one was designed for negative bending moment. Before strengthening, a static loading test was performed on the original connection. Thereafter, the steel connection was strengthened by using the method described above and tested again to compare with the original steel connection without strengthening. The results from the connection subjected to positive bending moment are reported this paper. The numerical models of the connection before and after strengthening are shown in Figure 10.

Results and discussion: The load-displacement relationship of the connection under positive bending moment obtained from tests and predicted by FEM are shown in Figure 11. It is found that the load-displacement curve from numerical analysis agrees well but

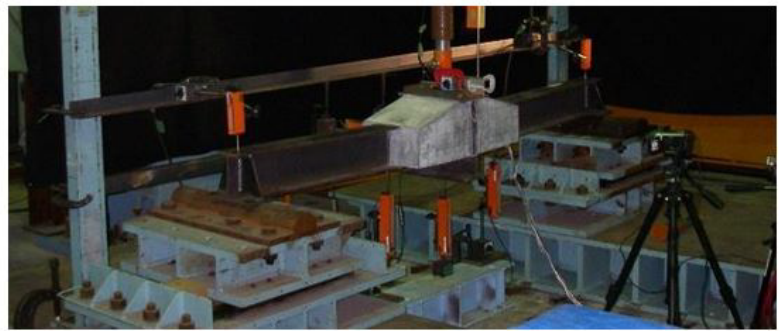

Figure 9: Test set-up.

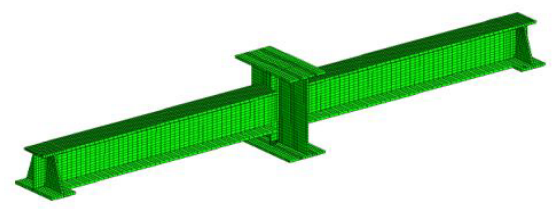

(a) Before strengthening

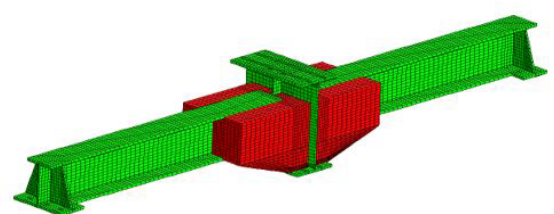

(b) Before strengthening

Figure 10: Numerical models.

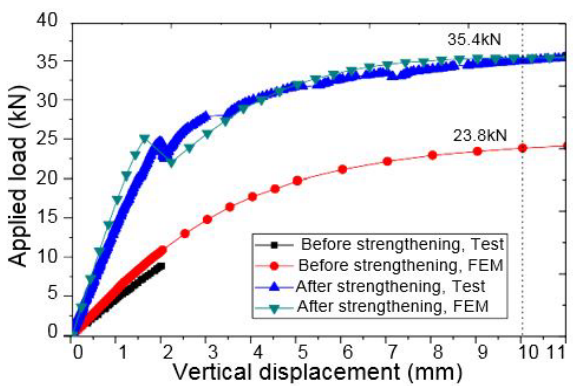

Figure 11: Load-deflection relationship.

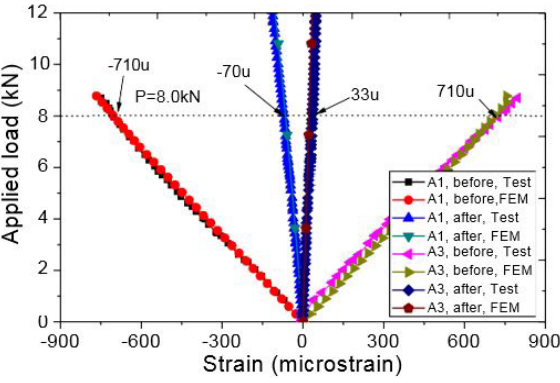

Figure 12: Strain development process (A-1, A-3).

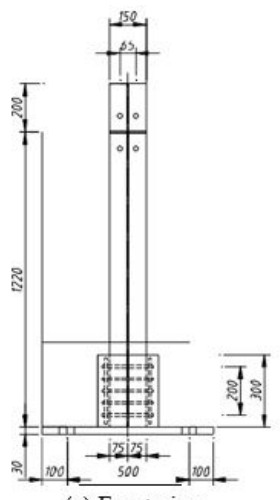

(a) Front view

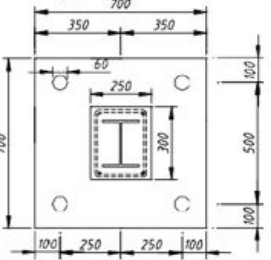

(c) Plane view

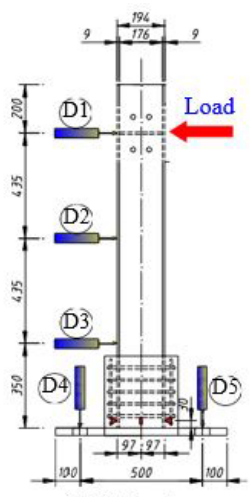

(b) Side view

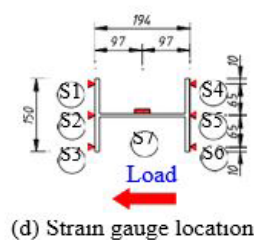

Figure 13: Size dimensions of column (strong axis, unit: $\mathrm{mm}$ ).

slightly stronger than those measured results, which might be due to unconsidered residual stress in the welding section. Moreover, for the strengthened joint, the numerical results has similar cracking load (Sudden drop point at the load of about $25 \mathrm{kN}$ ) and ultimate load carrying capacity with the test results. However, the rigidity of the strengthened joint is about 2.5 times of the original steel joint. In addition, the load carrying capacities of strengthened joint was also greatly increased. When the vertical displacement was $10 \mathrm{~mm}$, the corresponding applied load changed from $23.8 \mathrm{kN}$ in original steel connection to $35.4 \mathrm{kN}$ in strengthened connection, increasing by $48.7 \%$.

Figure 12 illustrates the sectional strain results of thesteel connection joints before and after strengthening. Measured points (A1 and $\mathrm{A} 3$ ) locate at $4 \mathrm{~cm}$ from the welding section at the span center, as shown in Figure 8. It can be found that the strain results from numerical analysis agree well with the experimental results, and the strain on strengthened connection was greatly reduced in comparison with the steel joint before strengthening. Taking the applied load of $8 \mathrm{kN}$ as an example, the corresponding normal strain at A1 was reduced from $-710 \mu$ in original connection to $-70 \mu$, indicating $90 \%$ strain reduction after strengthening. Similar results were also confirmed for A3 location (tension zone). According to the relationship between longitudinal strain and the fatigue load cycles for railway bridges proposed in MLIT [10], the service life can be greatly extended. Therefore, the fatigue life 
of the steel connection joint can be greatly extended, and the effects of the present strengthening method in strengthening existing steel connections can be confirmed.

\section{Case-3: Strengthening of existing columns}

Description of the test specimen: To simulate the steel column, an $\mathrm{H}$-shape steel column was designed. The specimen was $1.42 \mathrm{~m}$ in height, and the loading point was at the height of $1.2 \mathrm{~m}$. A $700 \mathrm{~mm}$ square steel plate with thickness of $30 \mathrm{~mm}$ was used as the base plate
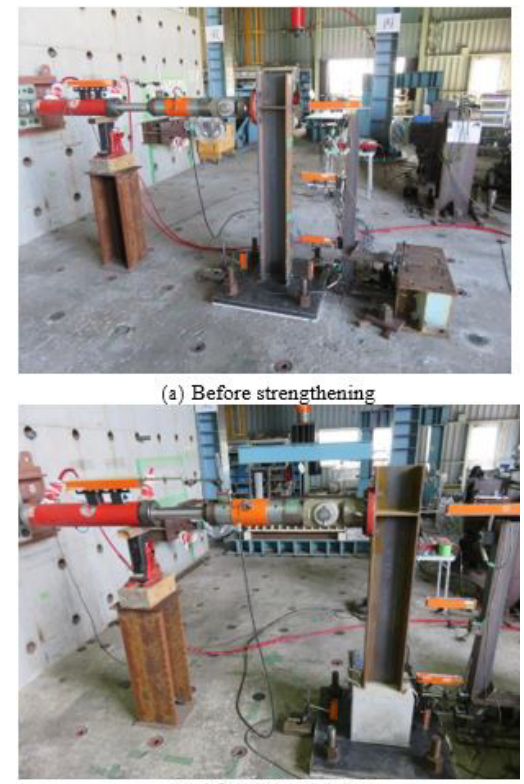

(b) After strengthening

Figure 14: Loading test setup.

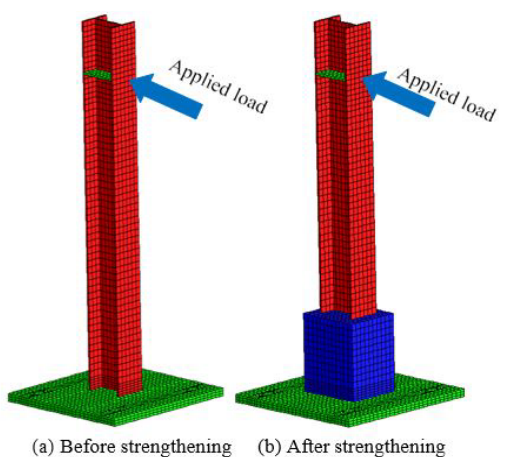

Figure 15: Numerical models of the columns.

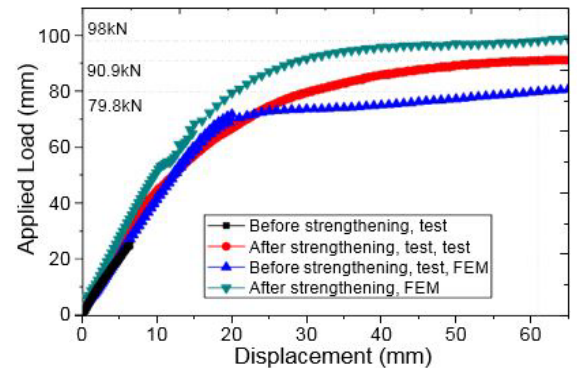

Figure 16: Load-displacement curve.

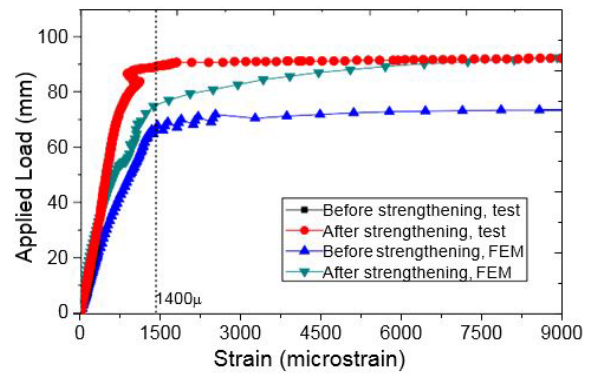

Figure 17: Load-strain curve.

and connected with the steel column by welding $[9,11]$. The typical geometry of the test specimen is shown in Figure 13. The test specimens were fixed through the base plate with the ground by using 4 bolts. The load applied by a jack in horizontal direction was used to simulate the earthquake load.

To show the effects of the proposed strengthening method, the results of the specimen under a load applied in strong axis direction were discussed as an example. The set-up of the static loading test is shown in Figure 14. Similar to the load test performed on the steel railway bridge superstructure and connections, static loading tests were performed on the specimen before strengthening. The load applied was smaller than the yield load to avoid possible damage or plasticity of the structural steel. Thereafter, the steel column was strengthened and tested again to compare with the results in the original steel pier without strengthening. Test results including horizontal displacement and normal strain in bottom section (with largest bending moment) were measured in the loading test. Numerical models for steel columns before and after strengthening were also built, as shown in Figure 15.

For the steel column under a load in the strong axis direction, the applied load and deflection relationship was given in Figure 16. From the results, significant increase of stiffness was also confirmed in the elastic stage. Also, the numerical results are close to but slightly stronger than those of the test results, and good agreement was confirmed as a whole. Also, the load carrying capacity of strengthened column was also obviously increased. Taking horizontal displacement of $61 \mathrm{~mm}$ $(=\mathrm{H} / 20)$ as an example, the corresponding applied load increased from $79.8 \mathrm{kN}$ in original steel column to $98 \mathrm{kN}$ in strengthened column, indicating $23 \%$ increase of the ultimate load.

The load-normal strain relationship is shown in Figure 17. Similar to the conclusions confirmed in the load- displacement curve, significant increase of the rigidity as well as the load carrying capacity can also be confirmed. Therefore, extension of residual service life in service condition and improvement of seismic performance during an earthquake for the column subjected to loads in weak axis direction can be confirmed. In addition, though slight difference was observed between numerical results and the test values, the numerical results can predict the test values in the whole loading process.

\section{Concluding Remarks}

A novel strengthening method for existing steel structures was reported in this paper. Rapid construction without impacting the public traffic and easy operated construction methods make this method competitive in comparison with other rehabilitation methods.

In order to confirm real effectiveness of this method, three applications on different steel railway structures were described in this paper. Static loading tests were performed on both original and strengthened steel structures, and detailed strain distribution on the 
Citation: Lin W (2018) Rehabilitation and Strengthening of Aged Steel Railway Bridges in Japan. J Civil Environ Eng 8: 305. doi: 10.4172/2165784X.1000305

steel members was reported in this paper. Loading tests were performed on short-span railway bridge superstructures and longitudinal and transverse beam connections. Obvious stress reduction was confirmed, indicating the great extension of their residual fatigue service life. Loading tests were also performed to investigate the proposed method in strengthening existing steel columns. Obvious reduction in flexural strain and significant increase of load carrying capacities were also confirmed, indicating the improvement of the seismic performance of the aged columns.

\section{Acknowledgments}

This is a collaborative research performed in Japan, many researchers including Associate Professor Nozomu Taniguchi from Maebashi Institute of Technology, Professor Teruhiko Yoda from Waseda University, Shinya Satake and Yusuke Sugino from the Taiheiyo Materials Corporation, and Masanori Hansaka from the Railway Technical Research Institute etc., were got involved in this research. This research received financial support from the Japan Society for the Promotion of Science (JSPS) and the Japan Iron and Steel Federation etc. These supports are gratefully acknowledged.

\section{References}

1. Tamakosh T, Okubo M, Yokoi Y (2014) Technical Note of National Institute for Land and Infrastructure Management, No.776.

2. Japan society of civil engineers (2007) Standard specification for concrete structures.
3. Nakasu M, Iwatate J (1996) Fatigue experiment on bond between concrete and reinforcement. Transaction of JSCE 426: 852-853.

4. Japan Society of Civil Engineers (2007) Standard specifications for steel and composite structures ( $1^{\text {st }}$ edn $)$.

5. Lin W, Yoda T, Taniguchi N, Koide N (2012) Numerical study on hybrid structures renovated from the old railway steel bridges. J Struct Engineer 58: 925-934.

6. Lin W, Yoda T, Taniguchi N, Hansaka M (2013) Performance of strengthened hybrid structures renovated from old railway steel bridges. J Constr Steel Res 85: 130-139.

7. Lin W, Yoda T, Taniguchi N (2014) Rehabilitation and restoration of old steel railway bridges: laboratory experiment and field test. J Bridge Eng 19: 04014004.

8. Lin W, Yoda T, Taniguchi N, Satake S, Kasano H (2014) Preventive maintenance on welded connection joints in aged steel railway bridges. J Constr Steel Res 92: 46-54.

9. Lin W, Taniguchi N, Yoda T (2017) Novel method for retrofitting superstructures and piers in aged steel railway bridges. J Bridge Eng 22: 05017009.

10. Ministry of Land, Infrastructure, Transport and Tourism (MLIT) (2009) Standard specification for railway structures.

11. Lin W, Taniguchi N, Yoda T (2017) A preventive strengthening method for stee columns: experimental study and numerical analyses. J Constr Steel Res 138 357-368. 